\title{
Resistance and Discontent via the Conceptual Metaphors of Belief Emerson's Self-reliance as a Case-Study
}

\author{
SawsanTrifi \\ Carthage University (ISLT)
}

\begin{abstract}
:
Resistance to the dominant value-system in literature has been a recurrent pattern throughout history. In more particular words, it has been brought to life each and every time that there was a crisis. The dispute over the abolition of slavery in $19^{\text {th }}$ century America is a prominent example (Filler, 1996). By investigating the conceptual metaphors of belief (Lakoff \& Johnson, 1980; 1999), the study aims at unveiling the dimensions of resistance and discontent in Emerson's essay Self-reliance. The task was ensured, by applying Critical Metaphor Analysis (CMA) (Charteris-Black, 2004) to literary discourse. Since this methodology has not applied to literary discourse, the present study intends to cover this lack as recommended by some scholars (Semino \& Steen, 2008; Wei Li, 2016). The results are significant in terms of two aspects: First, they showed that the source domains (SDs) of metaphors pertaining to belief conveyed the author's resistance to the Western dominant thought at three major levels: socio-cultural, political and philosophical. Second, the scrutiny of the individual and social resources of the conceptual metaphors of belief (Charteris-Black, 2004), permitted demonstrating certain metaphor properties as well as contesting the author's claimed rebellious thought. In conclusion, the skill to empirically study metaphorical patterns and plough them back to the field of rhetoric served the unmasking of the author's cultural and ideological motivations.
\end{abstract}

Keywords: CMA - literary discourse - metaphor properties - motivations - resistance resources source domains

(SDs). 
18-20 December, 2020

Oxford, United Kingdom $11^{\text {th }}$ International Conference on Humanities, Psychology \& Social Sciences

\section{Introduction:}

By empirically re-searching literature through the conceptual metaphors of belief, the paper aims at investigating the theme of resistance and discontent in literary discourse; especially, Emerson's essay Self-reliance. Disenchanted by science and technology, the author suggested spiritual experience through the culture of the East. By means of the conceptual metaphor of beliefs, he exerted a negative evaluation on the old belief-sets of his people and proposed the Eastern faiths instead. As a founding father of Transcendentalism, he showed resistance to the values of the Enlightenment and to the constraints of Materialism throughout his essay. In this case, resistance occurred by the centre itself, against the centre, and through bringing the culture of the periphery to the centre. Nonetheless, applying the methodology of Critical Metaphor Analysis (Charteris-Black, 2004) to the essay of Self-reliance led to other results. Indeed, examining the source domains of the conceptual metaphors of belief revealed a deterministic view where metaphors were pre-determined by the physical and cultural environment of the author. Besides, a close scrutiny of metaphor resources and metaphor choice permitted raising questions about Emerson's real intentions. The paper then undertakes to answer the following question: To what extent were the conceptual metaphors of belief successful in achieving the author's aims in this literary and in this "emancipatory" experience?

The study is organized into five parts: First, we offer a theoretical background including a brief introduction of Emerson's essay Self-reliance, a definition of conceptual metaphor, and a presentation of Critical Metaphor Analysis. Second, we delineate the methodology used to investigate the contribution of conceptual metaphor to the topic of resistance. Third, we present and discuss the results based on Critical Metaphor Analysis (CMA). Fourth, we present a summary of the main results. Finally, the paper concludes with the implications of the obtained results.

\section{Theoretical Background:}

\section{1. Self-reliance:}

By deferring certain values and displaying others, Emerson strongly established the value of Individualism in his most widely printed literary masterpiece Self-reliance. Over and over again, the writer suggested that the essence of individuality lied in the truths found within oneself and not those searched for in a value-crystallizing society. As he dwelt on instances from society, religion and philosophy, Emerson aimed at convincing the readership to resist all forms of the established beliefs. Furthermore, he contested the possibility that truth be with the other; be it society, the church or any of the political institutions. Emerson's philosophy reposed on subjective intuition rather than objective empiricism. Connectedly, he stated that: "No law can be sacred to me except that of our own nature [...] the only right is what is after my constitution the only wrong is what is against it" (Emerson, 2019: 11). To demonstrate the virtues of the notion of self-reliance, Emerson exploited examples from the natural surroundings and confirmed that: "Nature suffers nothing to remain in her kingdoms, the genesis and maturation of a planet, $[. .$.$] the vital resources of every animal and vegetable, are$ 


\section{8-20 December, 2020}

\section{Oxford, United Kingdom}

\section{$11^{\text {th }}$ International Conference on Humanities, Psychology \& Social Sciences}

demonstrations of the self-sufficing and therefore self-relying soul" (Ibid : 24). For their conservation and growth, these natural elements do not ask for support from elements that are strange to their cores. Similarly, becoming powerful only occurs when "a Man puts off all foreign support and stands alone" (Ibid: 33). Through a special emphasis on the concept of the self, Emerson mainly argued that not to conform is what creates great changes in the history of Mankind. The current study will employ the conceptual metaphors of belief, as a cognitive and discursive tool, to test what has been considered as Emerson's wisdom; in other terms, to answer a fundamental question: Was the author innocently preaching self-reliance and Individualism or were there any political unannounced reasons behind his "instructions"?

\subsection{Conceptual / cognitive metaphor:}

A conceptual metaphor takes the form of "A IS B" (e. g, TIME IS MONEY); that is, one domain of experience is systematically conceptualized in terms of another. For instance, in the statements: "This is a time-saving device. Don't watse your time. She spent some time in Paris", the italicized words are linguistic metaphorical realizations of the same conceptual metaphor TIME IS MONEY. We need metaphor because many concepts like TIME and EMOTIONS are not clearly delineated and we need other concepts to understand them in clearer terms like OBJECTS and SUBSTANCES (Lakoff \& Johnson, 1980). Consequently, metaphors are mental entities we live by, to use Lakoff and Johnson's words.

\subsection{Critical Metaphor Analysis (CMA)}

Critical Metaphor Analysis (CMA, hereafter) CMA is an approach to metaphor study that integrates Cognitive Linguistics (CL), Critical Discourse Analysis (CDA), and Corpus Linguistics (Charteris-Black, 2004). It aims at providing accuracy in metaphor identification, adding corpora to metaphor studies based on isolated instances and offering a pragmatic aspect to the cognitive analysis of metaphor. In fact, metaphor identification is based on the principle of semantic tension which only occurs when we have two different domains of experience and one domain of experience is perceived in terms of another TARGET-DOMAIN IS SOURCE-DOMAIN. However, metaphor identification requires more accuracy as semantic tension does not inform the researcher about whether a metaphor would be a morpheme, a phrase or a part of speech. In this paper, metaphor will be identified on the basis of lexical units. According to Steen, what counts as a lexical unit means that: "(1) All words provided with an independent Part-Of-Speech as POS tag in the corpus are taken as separate lexical units. (2) All so-called polywords in the corpus are taken as single lexical units" (2010:27). For illustration, a statement from Emerson's Self-reliance is used: "But in minds, the classification is idolized, passes for the end, and [passes] not for a speedily exhaustible means, so that the walls of the system blend to their eye*in the remote horizon with the walls of the universe; the luminaries of heaven seem to them hung on the arch their master built". Following Lakoff and Johnson (1980), the lexical units are italicized. Inspired by their Master Metaphor List (1999), the linguistic metaphors are determined. These linguistic metaphors are underlain by the following cognitive metaphors which are presented in an orderly manner.

\section{BELIEFS / CREEDS ARE SUBSTANCES IN A CONTAINER / THE MIND}

BELIEFS / CREEDS ARE STRATIFIED ENTITIES 
18-20 December, 2020

Oxford, United Kingdom $11^{\text {th }}$ International Conference on Humanities, Psychology \& Social Sciences

BELIEFS / CREEDS ARE IDOLIZED ENTITIES

BELIEFS / CREEDS ARE MOVING OBJECTS / ENTITIES dead mph

BELIEFS / CREEDS ARE DESTINATIONS / ENDS (x 2)

BELIEFS / CREEDS ARE MOVING ENTITIES (NOT) dead mph

BELIEFS / CREEDS ARE RESOURCES (NOT)

BELIEFS / CREEDS ARE MEANS (NOT)

BELIEFS / CREEDS ARE BUILDINGS / WALLS

To their eye : a polyword

BELIEFS / CREEDS ARE SUBSTANCES IN A CONTAINER / A SYSTEM

BELIEFS / CREEDS ARE BLENDED SUBSTANCES

BELIEFS / CREEDS ARE PERCEPTIONS

BELIEFS / CREEDS ARE SUBSTANCES IN A CONTAINER / THE HORIZON

BELIEFS / CREEDS ARE BUILDINGS / WALLS

BELIEFS / CREEDS ARE SUBSTANCES IN A CONTAINER

BELIEFS / CREEDS ARE SURFACES

BELIEFS / CREEDS ARE BUILDINGS / ARCH

BELIEFS / CREEDS ARE BUILDINGS

These mappings solve the cognitive incongruity created by semantic tension. The mnemonic A IS B is obtained by resorting to the cognitive dimension. This stage of metaphor analysis is called metaphor interpretation in CMA (Charteris-Black, 2004). Nevertheless, cognitive linguistics (CLs) does not present context for conceptual metaphors, neither does it account for the intentions of the producer's metaphorical utterances. As the deliberate projection of the target domain of belief (TD) into specific source domains (SDs, hereafter) are to reflect the author's intentions, it is necessary to move to a further stage; that is the stage of explanation. As metaphor is reputed for being full of ideology and deliberate (Goatly, 2007; Steen, 2008), the pragmatic dimension is required. By exploiting its property to hide certain 


\section{8-20 December, 2020}

\section{Oxford, United Kingdom}

\section{$11^{\text {th }}$ International Conference on Humanities, Psychology \& Social Sciences}

aspects and downplay others, the hidden attitudes of the author are unmasked. Moreover, metaphor favours a specific interpretation over another because of positive and negative evaluation frequently presented as instances of pragmatic meaning (Charteris-Black, 2004). To illustrate the stage of explanation, the cognitive metaphors mentioned above are used. Indeed, Emerson shows discontent with the old creeds by attributing a negative evaluation to BELIEFS ARE SUBSTANCES IN A CONTAINER, BELIEFS ARE STRATIFIED ENTITIES, BELIEFS ARE IDOLIZED ENTITIES, BELIEFS ARE MOVING ENTITIES, BELIEFS ARE DESTINATIONS / ENDS (x 2), BELIEFS ARE MOVING ENTITIES (NOT), BELIEFS ARE BUILDINGS, BELIEFS ARE BLENDED SUBSTANCES, BELIEFS ARE PERCEPTIONS, BELIEFS ARE SURFACES, BELIEFS ARE BUILDINGS (x 2). For example, the SD of CONTAINERS reflects the idea of restriction. While creeds are contained and constrained, the human mind is not free to create new thoughts. The SD of IDOLIZED ENTITIES stresses the idea of the impossibility of change. The SDs of MOVING ENTITIES, DESTINATIONS, MEANS, PERCEPTIONS, and BLENDED SUBSTANCES convey the people's confusion with the dominant belief-system. Since they do not distinguish between the established beliefs and the universal truths, people do not consider that belief system as a means or a matter of perception. Instead, they take it for an end and this prevents them from seeing or thinking beyond it. Similarly, BELIEFS ARE BUILDINGS, which is a recurrent pattern, shows that beliefs are only constructions the masters built. By unveiling this confusion, Emerson seems to be enticing the slaves to break the master / slave relationship. His final aim was to allow them to go beyond the political system that was enslaving them. In sum, negative evaluation attributed to most of the SDs of the conceptual metaphors, emphasized the author's rejection of the old creeds. Bringing the linguistic metaphors to their cognitive grounding and drawing on the historical metaphor resources have allowed for uncovering the author's intention which were not immediately transparent. This task was, ensured by Critical Metaphor Analysis (CMA).

\section{Method:}

The conceptual metaphors of belief in Self-reliance were selected to examine the topic of resistance and discontent for reasons that meet the researcher's criteria: (1) the intersection of linguistics and literature, (2) the abundance of conceptual metaphors pertaining to the target domain of belief (3) a close reading of Self-reliance showed that the essay targets the topic of resistance from many perspectives (4) conceptual metaphor, beliefs and resistance, all of these components have to do with cognition, which would enable a better understanding of the complex relationship between language, thought and the socio-political context.

The first operation was about scrutinizing Self-reliance in order to determine what CharterisBlack called "candidate metaphors" of belief. This stage was aided by the use of the Cambridge Dictionary to check whether certain linguistic expressions could be considered as beliefs or not. On the basis of semantic tension, metaphors and non-metaphors were demarcated. As a consequence, the qualitative analysis allowed for the classification of linguistic metaphors into beliefs and non-beliefs as well as the distinction of metaphors from non-metaphors. This operation depended also on my knowledge of the world as an analyst and resulted in the mnemonic BELIEF IS X with $\mathrm{X}$ referring to more than 400 source domains of experience (438). These were classified into 19 categories. Similarly, the quantitative analysis helped measuring the frequency of each source domain. Next, evaluation was utilized to determine whether the SDs were attributed a positive form of evaluation or a negative one. 
18-20 December, 2020

Oxford, United Kingdom $11^{\text {th }}$ International Conference on Humanities, Psychology \& Social Sciences

Afterwards, the quantitative analysis served measuring the percentage of the SDs which were, attributed a negative evaluation and the percentage of those which were given a positive judgment. Also, the most frequent SDs of experience were analyzed, and thus permitted determining thought patterns. Reading about the American history (Filler, 1996; Fredrickson, 1987; Kateb, 2002; Read, 2009; Steward, 2008) as well as the literary current (Goodman, 2003) to which the author belonged was necessary to unearth the ideological underpinnings of the metaphorical patterns. However, these patterns, were primarily justified by resorting to the individual and social resources of the metaphors of belief. Figure (1) displays a detailed content on metaphor resources.

INDIVIDUAL RESOURCES

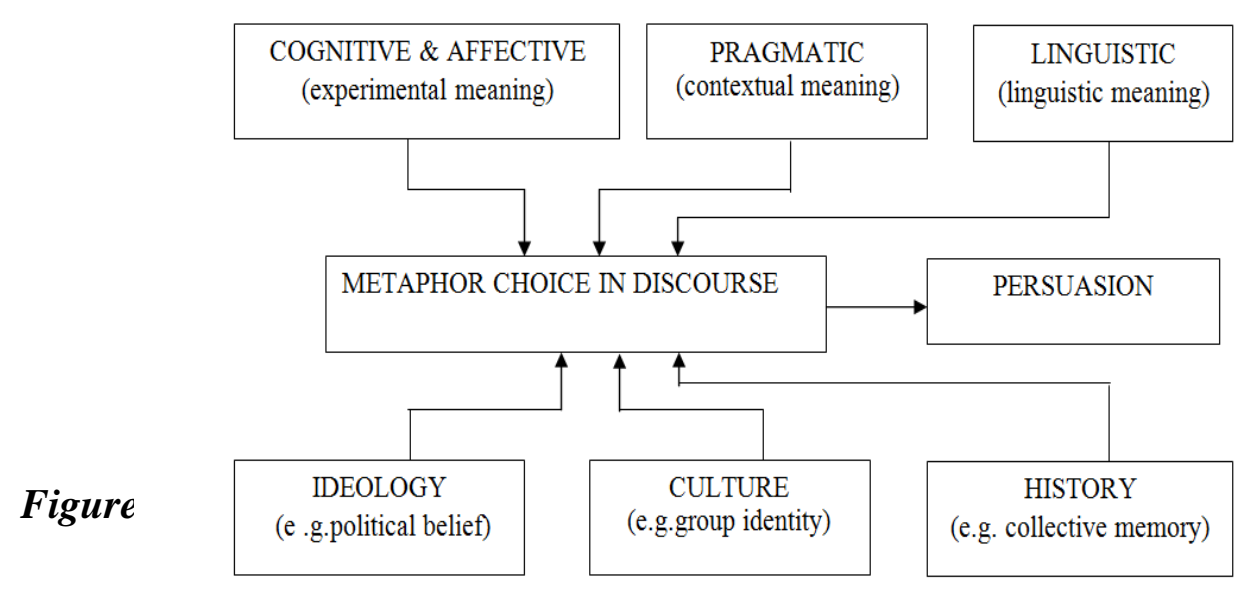

This model will

SOCIAL RESOURCES

ggered the conceptual metaphors of belief. On the one hand, the individual resources involve the cognitive and affective meaning, the pragmatic meaning and the linguistic meaning, that is, the experimental meaning, the contextual meaning, and the linguistic meaning of metaphors, respectively. The experimental meaning (cognitive and affective) could be illustrated by means of the origins of metaphors. In effect, metaphors emerged from our human everyday experience such as GOOD IS UP and BAD IS DOWN (Lakoff \& Johnson, 1980). The former metaphor, might have arisen for instance from experimental situations like a physical fight where the victor takes an upward position (Ibid). The latter, could have emerged from situations of illness and death in which people are found down or are put down (Ibid). On the other hand, the social resources include the ideological, the cultural and the historical resources. Examples presented by Charteris-Black (2004) include political belief, group identity and collective memory but there are certainly many more others. In this direction, Lakoff and Johnson (1980), suggest that GOD IS UP emerged from the fact that the concept of GOD represents the unknown so people attribute to it a physical orientation; ie, the idea of 
18-20 December, 2020

\section{Oxford, United Kingdom}

\section{$11^{\text {th }}$ International Conference on Humanities, Psychology \& Social Sciences}

being UP (an unreachable location). In other words, this model of analysis answers the fundamental question of Kovecses (2015), where [do] metaphors come from? Besides, metaphors shape beliefs because they repose on source domains of experience that people understand, and are familiar with (Charteris-Black, 2004). This is so because they emerged from their everyday practices and their everyday interaction with the physical and cultural environment (Lakoff \& Johnson, 1980). Indeed, when target domains of experience (ordinarily abstractions) are projected unto specific source domains of experience (ordinarily concrete entities), they direct the attention of the receivers to well-determined ideas (Goatly, 2007; Steen, 2008). In sum, the model equips the researcher with the individual and social resources of metaphor. The paper intends to show how these resources co-work to lead to persuasive acts as well as to the revelation of the author's intentions. This coincides with the stage of explanation under Critical Metaphor Analysis (CMA).

\section{Results and Discussion:}

The quantitative analysis revealed that the total number of the conceptual metaphors of belief reached 438. It also resulted in five major source domains depicting resistance: POSSESSIONS $23 \%$, OBJECTS $20 \%$, PEOPLE $15 \%$, CONTAINERS $11 \%$ and QUANTITIES $8 \%$. These results are illustrated in figure (2) placed downward. However, the rest of the metaphors of belief were scattered over other SDs like LOCATIONS, BUILDINGS and PLANTS. Also, classifying the source domains of the conceptual metaphors of belief in Self-reliance revealed multiple aspects of discontent with the dominant world view. In effect, the study demonstrated how metaphor served resistance while taking socio-cultural, political and philosophical dimensions. As these conceptual metaphors of belief were traced back to their individual and social resources, the study acquired a pragmatic aspect. Certain metaphor properties were consequently unveiled and the author's intentions which were "not immediately transparent"; to use Charteris-Black's terms, were unmasked.

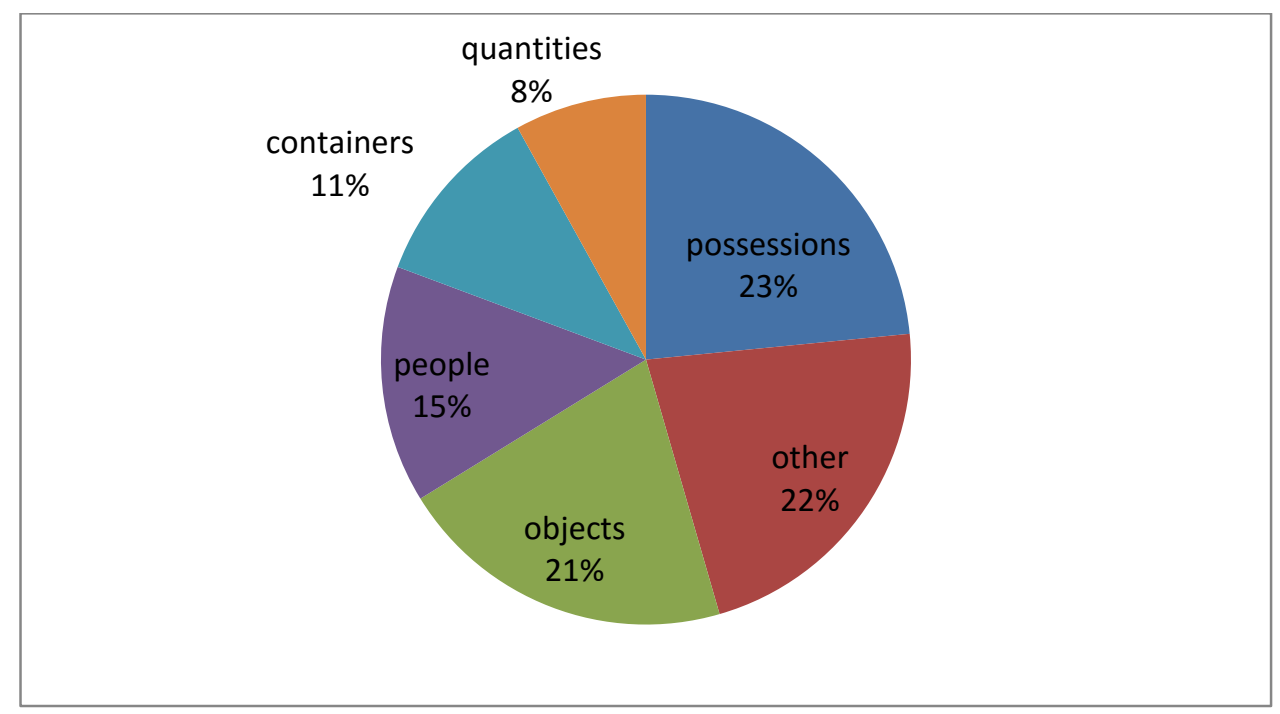


figure 2 : Major source domains pertaining to belief metaphors

\subsection{The socio-cultural dimension of resistance:}

The quantitative analysis of the conceptual metaphors of belief resulted in three major source domains depicting resistance from a socio-cultural perspective: POSSESSIONS 23\%, OBJECTS $20 \%$, and CONTAINERS $11 \%$. They mirrored Emerson's attitude towards the West trapped in its scientific mind and submerged in the materialistic achievements of its own making. With a quantity of $23 \%$, POSSESIONS ranked first in the distribution of source domains and carried a negative form of evaluation representing $49 \%$ as well as a positive one representing $40 \%$. The conceptual metaphor BELIEFS ARE POSSESSIONS with a negative judgment included possessions of the other. This is obvious in the utterance: "Yet, is the discontent of the multitude more formidable than that [discontent] of the senate and [the discontent of] the college". The linguistic metaphor "of" is triggered successively by the cognitive metaphors: AN ATTITUDE / DISCONTENT IS A POSSESSION OF THE MULTITUDE, AN ATTITUDE / DISCONTENT IS A POSSESSION OF THE SENATE, and AN ATTITUDE / DISCONTENT IS A POSSESSION OF THE COLLEGE. Emerson then rejected all beliefs resulting from social heritage, political affiliation, religious belonging and even those acquired by education. Alternatively, he attributed a positive judgment to BELIEFS ARE POSSESSIONS, as in: "To believe your own thought, to believe that what is true for you in your private heart is true for all men, - that is genius".

To further demonstrate his resistance to the beliefs of his nation, Emerson employed the conceptual metaphor BELIEFS ARE OBJECTS representing $20 \%$ of the total number of SDs. It conveyed a negative form of evaluation reaching up to $56 \%$ and included sub-metaphors like BELIEFS ARE HEAVY BURDENS, OPINIONS ARE SHARP INSTRUMENTS, BELIEFS ARE BINDING INSTRUMENTS and BELIEFS ARE PHYSICAL ATTACHMENTS. These sub-metaphors underlay linguistic metaphors like "drag about", "darts", "handkerchief", and "attached", respectively. Finally, Emerson thought that A BELIEF (OLD) IS AN OBJECT THAT SHOULD BE DESERTED as in "Leave your theory, as Joseph [left] his coat in the hand of the harlot, and flee". However, BELIEFS ARE OBJECTS with a positive judgment reached also an important percentage representing $42 \%$. This cognitive metaphor triggered the italicized linguistic metaphorical expressions in the statements: "Speak your latent conviction, and it shall be the universal sense; for the inmost in due time becomes the outmost, and our first thought is rendered back* to us by the trumpets of the Last Judgment", "A man should learn to detect and [a man should learn to] watch that gleam of light which flashes across his mind from within, more than the lustre of the firmament of bards and sages" and "This sculpture in the memory is not without pre-established harmony". In more particular terms, these statements included the sub-metaphors BELIEFS ARE OBJECTS THAT CAN BE RENDERED BACK TO ONESELF, BELIEFS ARE LIGHTS, and BLIEFS ARE WORKS OF ART, respectively. They predominantly conveyed spirituality, the importance of the self and of intuition. These metaphors were hence founded on references to the Eastern faiths.

Moreover, Emerson voiced his resistance to the inherited beliefs of his nation through the conceptual metaphors BELIEFS ARE CONTAINERS and BELIEFS ARE SUBSTANCES IN A 


\section{8-20 December, 2020}

\section{Oxford, United Kingdom}

\section{$11^{\text {th }}$ International Conference on Humanities, Psychology \& Social Sciences}

CONTAINER with a value of $11 \%$. Containers can be physical entities like clothes (prison uniforms) or body parts (the ear, the hand). They may also be mental entities like feelings (contempt, awe, terror), or attitudes (resistance, reverence, consistency). Quite often, these specific metaphors depicted a negative form of evaluation with $32 \%$. As the author contested the beliefs that have long been admitted as virtuous by his people, he endowed metaphors like BELIEFS ARE CONTAINERS OF VIRTUE and BELIEFS ARE STORES FROM WHICH PEOPLE DRAW OLD IDEAS with a negative charge. It is worth mentioning though, that Emerson utilized a higher percentage of containers conveying a positive judgment $(50 \%)$. This result was quite different from the general tendency; in that, the SDs predominantly communicated a negative judgment. However, positive evaluation, in this case led to a form of resistance and discontent as containers involved mental entities like solitude, self and soul and mirrored spirituality, freshness and distinction from the dominant thought patterns. These results are represented in the following table showing evaluation among the five most frequently used SDs. The rest of the SDs are scattered over several other domains of experience like buildings and plants.

\begin{tabular}{|c|c|c|c|c|c|c|c|}
\hline \multirow{2}{*}{ SDs } & \multicolumn{2}{|c|}{ Positive } & \multicolumn{2}{c|}{ Negative } & \multicolumn{2}{c|}{ Neutral } & Total \\
\cline { 2 - 9 } & Count & $\%$ & Count & $\%$ & Count & $\%$ & Count \\
\hline Possessions & 40 & $40 \%$ & 51 & $49 \%$ & 11 & $11 \%$ & 102 \\
\hline Objects & 38 & $42 \%$ & 50 & $56 \%$ & 02 & $2 \%$ & 90 \\
\hline People & 21 & $33 \%$ & 40 & $64 \%$ & 02 & $3 \%$ & 63 \\
\hline Containers & 23 & $50 \%$ & 18 & $32 \%$ & 08 & $18 \%$ & 49 \\
\hline Quantities & 06 & $19 \%$ & 19 & $59 \%$ & 07 & $22 \%$ & 32 \\
\hline Other & --- & --- & -- & --- & -- & --- & $102=22 \%$ \\
\hline
\end{tabular}

Table 1: Evaluation in the quantitatively dominant source domains (to be read horizontally)

Nonetheless, Emerson's declared discontent with his nation was not completely free from the culture he denounced. Bringing the linguistic metaphors back to their conceptual basis revealed the fact that these metaphors drew on historical, social and cultural resources (Charteris-Black, 2004). On the one hand, Emerson announced his rejection to all knowledge sources coming from the old continent. Yet, the conceptual metaphors he utilized demonstrated that these knowledge sources, meant for certain specific persuasive purposes, were heavily present. From the Greek philosophy, he employed BELIEF IS A COMMUNICATION OF VIRTUE, BELIEF IS A COMMUNICATION OF VICE, BELIEFS ARE CONTAINERS OF VIRTUE and BELIEFS ARE SHADOWS. These metaphors essentially recalled Plato's world view which was 


\section{8-20 December, 2020}

\section{Oxford, United Kingdom}

\section{$11^{\text {th }}$ International Conference on Humanities, Psychology \& Social Sciences}

also documented by some literary critics of Emerson (Filler 1996; Kateb, 2002). From the Judo-Christian faith, he employed BELIEFS ARE OBJECTS TO BE DESERTED LIKE JOSEPH'S COAT and BELIEFS ARE HEAVY BURDENS. From the Folk Theory of knowledge, he borrowed the orientational metaphors GOOD IS UP and BAD IS DOWN (Lakoff \& Turner, 1989); for example, BELIEFS ARE DESTINATIONS ABOVE WHICH MAN RISES, BELIEFS ARE OBJECTS LOCATED UPWARD ON A VERTICAL LINE, and BELIEFS ARE OBJECTS LOCATED DOWN A VERTICAL LINE. In sum, the author depended on the values of the old continent, of established religion, and of the Folk Theory of Knowledge. These, were resources so entrenched in the author's culture that they became determinant in the way Emerson "manufactured" his metaphors. On the other hand, the author strongly opposed the American society because it was submerged in the scientific practices of the era. However, unveiling the conceptual metaphors of belief in this essay showed that he was bound to use these resources for his persuasive purposes. The conceptual metaphor BELIEFS ARE OBJECTS and BELIEFS ARE QUANTITIES ranking second, and fourth in the distribution of (SDs), connoted the objectification of beliefs and reflected the author's belonging to a society of production. In this vein, the American socio-economic life underlay conceptual metaphors like BELIEFS ARE GAMBLING GAMES and BELIEFS ARE BANK TRANSACTIONS. In sum, these metaphors demonstrated the author's imprisonment in the socio-economic environment he apparently contested. Thus, the analysis of metaphor resources, upon which Critical Metaphor Analysis (CMA) is constructed, provided proofs for the deterministic attitude towards metaphor. In spite of Emerson's claimed resistance to the dominant thought through certain metaphors, other metaphors "resisted" resistance as were pre-determined by the individual and social resources.

\subsection{The political dimension of resistance:}

The results showed that Emerson drew on historical and ideological resources from his own country to demonstrate resistance and discontent. Indeed, the quantitative mode of analysis demonstrated that BELIEFS ARE PEOPLE and BELIEFS ARE CONTAINERS held a political dimension of resistance. First, BELIEFS ARE PEOPLE holding a value of $14 \%$ in the distribution of SDs was not free from political propositions. This metaphor conveyed resistance to the old continent with negative evaluation rising up to $64 \%$. It also suggested a new value system based on Individualism and self-reliance with positive evaluation representing 33\%. For example, the sub-metaphors: BELIEFS ARE DEAD BODIES and BELIEFS ARE OPPONENTS, depicting a negative judgment, aimed at revolutionizing the minds against the old system. The former underlay linguistic metaphorical realizations in Self-reliance like "faceless body", "disfigured body", and "corpse" while the latter motivated linguistic metaphorical manifestations like "It scatters your force", "It loses your time", and "It blurs your vision". These linguistic and conceptual metaphors are further illustrated in figure (3). 


\section{8-20 December, 2020}

\section{Oxford, United Kingdom}

$11^{\text {th }}$ International Conference on Humanities, Psychology \& Social Sciences

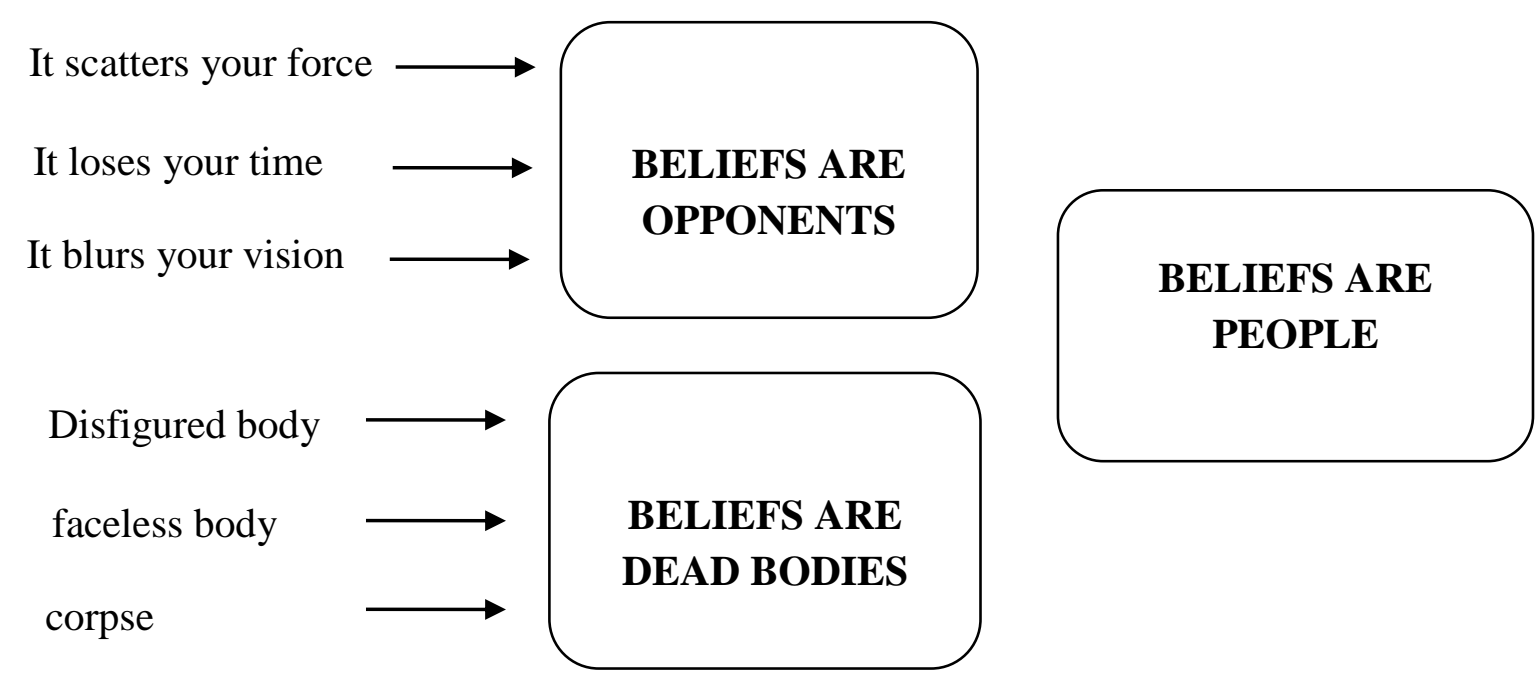

Figure 3: An illustration of the conceptual metaphor BELIEFS ARE PEOPLE, sub-metaphors and linguistic metaphors.

Besides, BELIEFS ARE ENTITIES WITH HUMAN ATTRIBUTES, conveying a positive evaluation such as the sub-metaphor BELIEFS ARE LIVING ENTITIES, carried the idea that Man should be constantly re-inventing himself to reach for the Over-soul (Goodman, 2003). Emerson was indeed, telling the Afro-Americans that re-creating a new status was possible for them. Hence, these metaphors motivated resistance to the strongly established slavery system.

In addition, Emerson employed CONTAINERS as SDs, to which he attributed a positive judgment with a value of $50 \%$, for his political purposes. Containers predominantly referred to THE SELF and THE SOUL as in:"If we ask whence this comes, if we seek to pry into the soul that causes, all philosophy is at fault. Its presence or its absence is all we can affirm". In effect, "Whence" and "into" are linguistic metaphors that triggered the cognitive metaphor THOUGHT / PHILOSOPHY IS A SUBSTANCE IN A CONTAINER. Nonetheless, containers were not meant to innocently echo spirituality. Instead, they were intended for a new mental construction; that of the desire for becoming self-dependent and thus resisting slavery. In his essay of Self-reliance, Emerson strongly recommended rebellion as in "And we are now men... and not minors and invalids in a protected corner, not cowards fleeing before a revolution" (2019: 10). Emerson the abolitionist is, said to have enticed the individual fugitive slaves to become self-reliant (Steward, 2008). The question that arises from this situation is: Did the White Anglo-Saxon author really sympathize with the Black Afro-American; in other words, was he truly altruistic towards them? Emerson's essay Self-reliance is believed to have been intended to free the slaves from the plantations. The aim was to push them to move northward in order to provide the factories with the badly needed work force (Fredrickson, 1987; Kateb, 2002). It was even reported in the literature that he was skeptical about the black capacity (Read, 2009). In this vein, the conceptual sub-metaphor BELIEFS ARE SERVANTS showed that Emerson was not a radical abolitionist. Furthermore, his statement: "Let us enter into the state of war, and wake Thor and Woden, courage and constancy, in our Saxon breasts" (2019: 25) uncovered his belief in the superiority of the white race. As a result, Critical Metaphor Analysis based on the revelation of the ideological and historical resources 


\section{8-20 December, 2020}

\section{Oxford, United Kingdom}

\section{$11^{\text {th }}$ International Conference on Humanities, Psychology \& Social Sciences}

of metaphors, unmasked some of the author's hidden intentions. In this direction, Read argued that: "His ideal of self-reliance is in the end more suited to a reasonably peaceful, lawgoverned democracy characterized by free and equal individuals than to a world of masters and slaves, or a nation on the brink of civil war" (2009: 1). This disillusioned attitude supported the idea that self-reliance was to some extent a cover-term used in a twisted manner for economic and political purposes. Thus, the notion of self-reliance; in particular, with regard to the institution of slavery was simply a mock resource for Emerson's metaphors.

\subsection{The Philosophical dimension of resistance:}

The philosophical dimension of resistance relative to Transcendentalism; was particularly voiced through the cognitive metaphor BELIEFS ARE QUANTITIES. Indeed, the results of the quantitative analysis have shown that quantity was the fifth most important source domain pertaining to beliefs. One striking result in this analysis was that the SDs of quantity showed a relatively high percentage in terms of neutrality. It even over-rode positive evaluation ( $22 \%$ vs 19\%). The cognitive metaphor BELIEFS ARE QUANTITIES with a neutral attitude; for example, underlay the italicized metaphorical utterances in: "Speak what you think now in hard words, and to-morrow speak what to-morrow thinks in hard words again, though it contradicts every thing you said to-day", One tendency unites them all", and "All things are made sacred by relation to it, - one as much as another". This deviation from the norm could be explained by the fact that this metaphor is entrenched in the Western culture (Grady, 1997).

Next, negative evaluation representing $59 \%$ was given to the SD of quantity. First, Emerson's statement: "The sentiment they instil is of more value than any thought they may contain", involved two cognitive metaphors which are THOUGHTS ARE QUANTITIES THAT ARE OF LESS VALUE THAN SENTIMENT and THOUGHTS ARE QUANTITIES. Not only did these metaphors hold a negative evaluation of thoughts but they also showed the importance of "sentiment" for Emerson, the Transcendentalist. In the statement: "If we ask whence this comes, if we seek to pry into the soul that causes, all philosophy is at fault", the linguistic metaphorical realization "all" was triggered by the cognitive metaphor THOUGHT / PHILOSOPHY IS A QUANTITY. In addition, number which is a variant of the SD of quantity, carried a negative evaluation. For instance, the linguistic metaphorical representation "one" was motivated by the cognitive metaphor ATTITUDE / POLITICAL AFFILIATION IS A QUANTITY. It occurred twice in the statement, "Meantime nature is not slow to equip us in the prison-uniform of the party to which we adhere. We come to wear one cut of face and [we come to wear one cut of] figure, and [we come to] acquire by degrees the gentlest asinine expression. In sum, Emerson expressed discontent with all sorts of beliefs that belonged to the past and to the other.

In contrast, positive evaluation representing only \%19 was attributed to the SD of quantity as in "Speak your latent conviction, and it shall be the universal sense; for the inmost in due time 


\section{8-20 December, 2020}

\section{Oxford, United Kingdom}

\section{$11^{\text {th }}$ International Conference on Humanities, Psychology \& Social Sciences}

becomes the outmost, and our first thought is rendered back to us by the trumpets of the Last Judgment". The linguistic metaphorical expression "first" was motivated by A BELIEF / A CONVICTION IS A QUANTITY / NUMBER, which stressed the importance of intuitive thought. Then, Emerson presents his world-view by stating that: "All things are dissolved to their centre by their cause and, in the universal miracle, petty and particular miracles disappear". The metaphorical utterance "petty" is underlain by BELIEFS ARE QUANTITIES / SIZE. The author's world-view is further illustrated in his statements "For of one will, the actions will be harmonious, however unlike they seem" and "One tendency unites them all". The linguistic metaphor "one", to which Emerson attributed a positive judgment, is underlain by the cognitive metaphors AN ATTITUDE / AN INTENTION / A WILL IS A QUANTITY and THOUGHT IS A QUANTITY, respectively. In sum, Emerson seemed to resist a value-system based on the old doctrines and to present a value-system founded on sentiment and intuition. However, the metaphor of QUANTITY revealed that as an academic authority and a political figure, the author was also trying to impose another value-sytem. Indeed, the linguistic metaphor "one" echoed the one-option thought and therefore transpired totalitarianism. In other terms, the writer was only reproducing the established system that is not open to diversity, and much less to freedom of choice. Actually, Emerson was an academic authority and a metaphor manufacturer whose attempt at imposing his world-view was, in itself a sort of chain he put around his audience. According to Lakoff and Johnson (1980), the people who manage to impose their metaphors are the people who manage to define truth. Finally, applying CMA to the metaphors of quantity in Self-reliance permitted the unmasking of pragmatic meanings. These, were related to the auhtor's intentions which were not immediately transparent in the linguistic metaphorical expressions.

\section{Summary:}

In this study of the conceptual metaphors of belief, Critical Metaphor Analysis (CMA) allowed for a better understanding of the topic of resistance and discontent. On the one hand, the quantitative analysis of the conceptual metaphors of belief demonstrated a polarity based on attributing privilege to a new set of beliefs while contesting the old ones. In fact, positive evaluation was given to SDs predominantly referring to spirituality and the resourceful self. However, negative evaluation was attributed to SDs referring to materialism and the institutionalized thought. Whereas the former SDs drew on the Eastern faiths, the latter emerged from the Western thought. As far as the first five major source domains of experience were concerned, the general tendency involved negative evaluation to convey the theme of resistance and discontent. It is worth mentioning though, that Emerson utilized a larger number of containers that carried a positive judgment (50\% vs 32\%) for negative evaluation. This is because containers referred to THE SELF AS A RESOURCE which emerged from the Eastern Faiths; particularly, Hinduism, Buddhism, and the Baha-i faith. Besides, Emerson suggested the idea that each individual in America should invent his own values, which emphasized the principle of self-reliance. He stressed the idea that beliefs were not fixed thoughts pertaining to the past neither, were they absolute truths dictated by the others. However, certain aspects were hidden and others were highlighted in the metaphors he employed; for example, Emerson's support for the slaves was highlighted but politically siding with the Northern states was covered. This meant that behind Idealism, there was an economic interest. In more general terms, conceptual metaphor showed that certain aspects of 


\section{8-20 December, 2020}

\section{Oxford, United Kingdom}

\section{$11^{\text {th }}$ International Conference on Humanities, Psychology \& Social Sciences}

belief in self-reliance were displayed while others, which did not serve the author's purposes, were masked. The individual and social resources of these metaphors of belief permitted revealing the author's real intentions as an abolitionist. Thus, the stage of metaphor explanation in CMA demonstrated the role of agency in leading an act of persuasion.

\section{Conclusion:}

The study demonstrated that Critical Metaphor Analysis (CMA) offered a large space to debate the dynamics of resistance and discontent in literary discourse. Once the conceptual metaphors of belief were displayed, the openly voiced attitudes became quite incongruous with those that were underlain. As a result, this metaphor study served uncovering dominance, manipulation and indoctrination and stressed the discursive function of metaphor. In addition, a close scrutiny of the metaphors of belief in Self-reliance revealed that conceptual metaphors may "resist" resistance; in other words, the author was compelled to render this predetermined character of metaphor. The study then demonstrated what might be called the paradox of metaphor since it was both determinant in the understanding and shaping of beliefs and pre-determined by our environment. At times, metaphors conveyed resistance. At other times, they showed conventional thought patterns. As a result, a sense of dilemma arose from Emerson's metaphors. Philosophically speaking, Self-reliance demonstrated the fact that we were in a middle position between resistance and fatalism. Historically speaking, we were in the middle of a political crisis. In this vein, Read acknowledged that: "In the 1860 essay Fate, Emerson reformulates the ideal of self-reliance [...] only through cold-eyed recognition of necessity can one preserve a measure of self-reliance in a world that frustrates our will" (2009 : 1). It would be significant to mention that resistance towards the traditional thought through literature is a recurrent pattern in history. It is brought to life each and every time that there is a crisis; for instance, the dispute over the abolition of slavery in $19^{\text {th }}$ century America. Also, a prominent example was the cultural resistance the world witnessed during the Youth Revolution of the late 1960s. However, there has been a dubious hidden agenda of some agency which can be explained by Emerson's statement in Self-reliance: "When the unintelligent brute force that lies at the bottom of society is made to growl and mow, it needs the habit of magnanimity and religion to treat it godlike as a trifle of no concernment" (2019: 14). Each time that there is a crisis, literature is; at least in part, engaged in Transcendentalism, Neo-romanticism or the spiritual. This has actually been a capitalist instrument to silence the rebellious voices and drive the masses towards passivity. Instead of asking for one's material and real rights in leading a decent life, a sense of illusory contentment is created through resorting to nature, spirituality and sometimes the moralizing discourse. Thus, Emerson the scholar and the politician, was himself active in selling an illusion; that of self-reliance.

\section{Further Research:}

The paper brought about a methodological import in that it applied Critical Metaphor Analysis (CMA) to literary discourse. Indeed, this methodology has exclusively been applied to political discourse, religious discourse and media reports. Adding literature to the corpora studied under CMA, served the interlacing of literature with politics. As it is a combination of 


\section{HPSCONF}

18-20 December, 2020

Oxford, United Kingdom $11^{\text {th }}$ International Conference on Humanities, Psychology \& Social Sciences

cognitive linguistics and Critical Discourse Analysis, CMA is also said to have "plough[ed] back the rhetorical element into metaphorolgy" (Forceville, 2006: 403), which dates back to Aristotle. What is novel though is the aim of this instrument as we do not just receive metaphor like passive consumers but we put this device to close scrutiny and accurate examination. Applying CMA to other corpora from literature would be a possible way to aid understanding and trigger critical thinking. Therefore, we recommend that more literary discourse be investigated under Critical Metaphor Analysis (CMA).

\section{Bibliography:}

Black, C.J. (2004). Corpus approaches to critical metaphor analysis. Springer.

Filler, L. (1996). Arguing About Slavery: The Great Battle in the United States Congress.

Forceville, C. (2006). Book Review: Corpus Approaches to Critical Metaphor Analysis. Language and Literature, 15(4), 402-405.

Fredrickson, G. M. (1987). The black image in the white mind: The debate on Afro-American character and destiny, 1817-1914. Wesleyan University Press.

Goatly, A., \& Goatly, A. (2007). Washing the brain: Metaphor and hidden ideology (Vol. 23). AmsterdamPhiladelphia: John Benjamins Publishing Company.

Goodman, R. (2003). Transcendentalism. Retrieved from https://scholar.google.com/scholar

Grady, J. (1997). Foundations of meaning: Primary metaphor and primary senses. Doctoral thesis. Linguistics Dept., University of California, Berkeley, 1997a/Grady J.

Kateb, G. (2002). Emerson and Self-reliance. Rowman \& Littlefield Publishers.

Kövecses, Z. (2005). Metaphor in culture: Universality and variation. Cambridge University Press.

Kövecses, Z. (2015). Where metaphors come from: Reconsidering context in metaphor. Oxford University Press, USA.

Lakoff, G., Espenson, J., \& Schwartz, A. (1991). Master metaphor list. Second draft copy. University of California at Berkeley.

Lakoff, G., \& Johnson, M. (1980). Metaphors we live by. The University of Chicago Press, Ltd. London

(1999). Philosophy in the Flesh: The Embodied Mind and Its Challenge to Western Thought. New York: Basic Books.

Lakoff, G., \& Turner, M. (1989). More than Cool Reason: A Field Guide to Poetic Metaphor. Chicago/London: The University of Chicago Press. 
18-20 December, 2020

Oxford, United Kingdom $11^{\text {th }}$ International Conference on Humanities, Psychology \& Social Sciences

Li, W.(2016). Rethinking critical metaphor analysis. International Journal of English Linguistics, 6(2), 92-98.

Semino, E., \& Steen, G. (2008). Metaphor in literature. The Cambridge handbook of metaphor and thought, 232-246.

Steen, G. (2008). The paradox of metaphor: Why we need a three-dimensional model of metaphor. Metaphor and Symbol, 23(4), 213-241.

Steen, G. (Ed.). (2010). A method for linguistic metaphor identification: From MIP to MIPVU (Vol. 14). John Benjamins Publishing.

Steward, James Brewer, (2008). Abolitionist Politics and the Coming of the Civil War. Amherst: University of Massachusetts Press, 2008.

\section{Sitography}

Emerson, R. W. (2019). Self-reliance. Retrieved from Lulu. com.

Lakoff, G. (1993). The Contemporary Theory of Metaphor. Retrieved from https://escholarship.org/uc/item/4nv3i5ig

Read, J. H. (2009). The Limits of Self-Reliance: Emerson, Slavery, and Abolition. Retrieved from

https://digitalcommons.csbsju.edu/cgi/viewcontent.cgi?article=1025\&context=polsci_pubs

The Cambridge Dictionary. Retrieved from https://dictionary.cambridge.org/ 